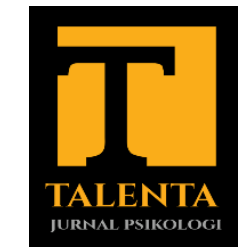

\author{
Volume 6 No 1 September 2020 \\ p-ISSN: 2460-8750 e-ISSN: 2615-1731 \\ https://doi.org/10.26858/talenta.v6i1.13041
}

\title{
PERAN IKLIM ORGANISASI TERHADAP WORK ENGAGEMENT DENGAN OPTIMISME SEBAGAI MEDIATOR
}

\author{
Rezky Ariany Arasi), Avin Fadilla Helmi ${ }^{2)}$ \\ Universitas Hasanuddin ${ }^{1)}$, Universitas Gadjah Mada ${ }^{2)}$ \\ rezkyariany@gmail.com ${ }^{1}$, avinpsi@gmail.com $^{2}$ )
}

\begin{abstract}
.
Work engagement has been studied including the antecedents, which are job resources and personal resources. However only a few studies have demonstrated predictors and outcomes of work engagement on an ongoing basis. There are six areas of work life potentially provide a way to conceptualize the climate for engagement. When measured as the climate construct (at the level of unit or organization), six areas of work life (workload, control, reward, community, fairness, and values) can influence employee perceptions of job demands and job resources, which in turn affects work engagement. On the other hand optimism becomes more prominent and better predictor of the work engagement. Result shows optimism ism is partial mediator of organizational climates' influence toward work engagement.
\end{abstract}

Keywords: work engagement, organizational climate, optimisme.

\begin{abstract}
ABSTRAK.
Work engagement telah banyak diteliti termasuk didalamnya antesedennya yaitu job resources dan personal resources. Meskipun demikian sangat sedikit studi yang menunjukkan prediktor maupun hasil dari work engagement yang secara berkelanjutan. Terdapat enam komponen kehidupan kerja yang berpotensi sebagai jalan untuk mengonsepkan climate for engagement. Ketika diukur sebagai konstruk iklim (pada tingkat unit atau organisasi), enam komponen kehidupan kerja (beban kerja, kontrol, reward, komunitas, keadilan, dan nilai-nilai) dapat mempengaruhi persepsi karyawan terhadap tuntutan pekerjaan dan sumber daya kerja, yang pada gilirannya mempengaruhi work engagement. Sementara pada satu sisi optimisme menjadi lebih menonjol dan merupakan prediktor yang lebih baik terhadap work engagement di bawah kondisi kerja tertentu. Hasil analisis menunjukkan bahwa optimisme dapat menjadi mediator parsial atas pengaruh iklim organisasi terhadap work engagement
\end{abstract}

Kata kunci: work engagement, iklim organisasi, optimisme.

\section{PENDAHULUAN}

Schaufeli dan Bakker (2004) mengemukakan bahwa work engagement merupakan suatu kondisi dimana individu memiliki pikiran yang positif serta memiliki motivasi yang tinggi dalam kaitannya dengan pekerjaannya. Kondisi tersebut ditandai dengan semangat yang tinggi (vigor), dedikasi (dedication), dan kedalaman fokus (absorption). Beberapa hasil penelitian menunjukkan bahwa anteseden dari work engagement adalah job resources (Bakker \& Xanthopoulou, 2013; Salanova \& Schaufeli, 2008; Schaufeli\& Bakker, 2004), dan personal resources yang mencakup, self efficacy (Federici \& Skaalvik, 2011; Simbula, Guglielmi, \& Fraccaroli, 2011), resilience (Othman, Ghazxali, \& Ahmad, 2013), ataupun personal 
resources secara umum (Bakker \& Xanthopoulou, 2013; Xanthopoulou, dkk, 2009). Job resources mengacu pada aspek-aspek fisik, sosial, maupun organisasi yang berfungsi sebagai media dalam pencapaian tujuan, sementara personal resources merupakan evaluasi diri yang positif yang mengacu pada perasaan individu mengenai kemampuannya dalam mengontrol dan mempengaruhi lingkungannya dengan sukses (Bakker \& Demerouti, 2007). Meskipun demikian sangat sedikit studi yang menunjukkan prediktor maupun hasil dari work engagement yang secara berkelanjutan dalam satu model yang lebih menyeluruh (Bakker \& Xanthopoulou, 2013).

Gagasan iklim organisasi merupakan dasar untuk mempelajari organisasi dan secara luas dianggap sebagai faktor penentu penting dari hasil sikap, perilaku, dan kinerja terkait (Reichers \& Schneider, 1990). Bakker, Albrecht, dan Leiter (2011) mengemukakakan bahwa terdapat enam komponen kehidupan kerja berpotensi sebagai jalan untuk mengonsepkan "climate for engagement". Adapun keenam komponen tersebut, yaitu beban kerja, kontrol, reward, komunitas, keadilan, dan nilai-nilai (Leiter \& Maslach, 2005). Keenam komponen tersebut telah dikaitkan baik secara teoritis maupun empiris dengan burnout dan engagement (Laba, 2012; Neiva \& Nery, 2012). Selanjutnya, ketika diukur sebagai konstruk iklim (pada tingkat unit atau organisasi), enam komponen dapat dimodelkan untuk mempengaruhi persepsi karyawan terhadap tuntutan pekerjaan dan sumber daya kerja, yang pada gilirannya telah terbukti mempengaruhi engagement (Bakker, dkk. 2011).

Hasil penelitian longitudinal yang dilakukan oleh Maslach dan Leiter (2008) pada 466 karyawan menunjukkan bahwa ketidakkonsistenan pada enam area kerja membuat karyawan cenderung untuk berubah dan mengalami burnout pada pengukuran kedua. Lebih lanjut Bakker, dkk. (2011) menyatakan bahwa ketika karyawan merasa bahwa organisasi mereka memberikan dukungan, melibatkan, dan memberikan iklim yang menantang, yang karenanya mengakomodasi kebutuhan psikologis karyawan, karyawan lebih cenderung untuk merespon dengan investasi waktu dan energi serta menjadi terlibat secara psikologis dalam pekerjaan organisasi mereka.

Work engagement merupakan variabel kunci atau mekanisme jelas yang menjelaskan bagaimana variabel kontekstual seperti iklim dan sumber daya pekerjaan mempengaruhi variabel hasil organisasi (Bakker, dkk., 2011). Lebih lanjut Bakker dan Sanz-Vergel (2013) mengemukakan bahwa karyawan yang engaged memiliki kecenderungan untuk percaya bahwa mereka umumnya akan mengalami hasil yang baik dalam hidup. Scheier dan Carver (1985) mengemukakan bahwa optimisme dan pesimism dapat didefinisikan sebagai kecenderungan umum untuk mengharapkan hasil positif atau negatif dalam kehidupan seseorang. Peterson dan Bassio (2002) mendefinisikan optimisme sebagai suatu keyakinan yang menyebabkan individu untuk mendekati dunia secara aktif. Individu yang optimis percaya bahwa masa depan merupakan peluang positif dengan hasil yang sukses.

Terdapat beberapa penelitian terkait mengenai peran optimisme. Peterson (Jezzi, 2006) menyatakan bahwa individu yang optimis secara aktif engaged terhadap apa yang dikerjakannya. Lebih lanjut Bakker dan Sanz-Vergel (2013) menyatakan bahwa optimisme menjadi lebih menonjol dan merupakan prediktor yang lebih baik terhadap work engagement di bawah kondisi kerja tertentu. Konsep The Job Demands-Resources model yang dikembangkan oleh Schaufeli dan Bakker (2004) menyatakan bahwa karakteristik lingkungan kerja dapat diklasifikasikan ke dalam dua kategori umum yaitu job demands dan resources. Tingkat tuntutan pekerjaan yang tinggi dan sumber daya yang terbatas dalam hal ini optimisme cenderung mengakibatkan gangguan kesejahteraan dan mencegah pencapaian tujuan karyawan. Selain itu, The $J D-R$ model juga menunjukkan bahwa job resources bersama dengan personal resources memberikan dampak pada keterlibatan dan kesejahteraan karyawan (Bakker \& Demerouti 2007). 
Berdasarkan dari JD-R model yang telah dikembangkan Xanthopoulou, dkk. (2007), peneliti tertarik untuk mengetahui bagaimana iklim organisasi yang dalam hal ini konteksnya dapat berupa job demands dan job resouces yaitu beban kerja, kontrol, reward, komunitas, keadilan, dan nilai-nilai dalam mempengaruhi optimisme pada karyawan yang pada akhirnya dapat membuat karyawan engaged terhadap profesinya.

\section{METODE}

Penelitian ini merupakan penelitian kuantitatif. Sampel dalam penelitian ini adalah karyawan yang telah bekerja minimal 2 tahun sehingga jumlah subjek penelitian ialah 165 karyawan. Rentang usia subjek berkisar antara 22 tahun hingga 56 tahun dengan masa kerja yang berkisar 2 hinga 36 tahun. Tingkat pendidikan subjek adalah SLTA/SMA/SMK, D3, S1, dan S2.

Penelitian ini dilakukan dengan menggunakan tiga skala sebagai alat ukur untuk ketiga variabel yang diuji oleh peneliti. Skala work engagement yang digunakan merupakan Utrecht Work Engagement Scale (UWES) yang dikembangkan oleh Schaufeli dan Bakker (2004) dengan reliabilitas cronbach's alpha 0.93 dan nilai factor loading berkisar antara 0.65-0.90.

Skala iklim organisasi yang digunakan merupakan skala adaptasi dari The Areas of Worklife (AWS) yang dikembangkan oleh Leiter dan Maslach (2011). The AWS merupakan alat ukur yang terdiri dari 28 aitem yang bertujuan untuk mengidentifikasi enam area dari organisasi, yaitu work load, control, reward, community, fairness, dan values. Cho, dkk. (2006) menunjukkan reliabilitas cronbach alpha dari skala adalah 0.89. sementara nilai factor loadings diperoleh dari 28 aitem dari enam sub-skala iklim organisasi menunjukkan skor $>0.50$. Hasil tersebut menunjukkan hubungan yang sempurna antara item, dimana aitemaitem tersebut merupakan kesatuan alat ukur yang dapat digunakan untuk mengukur konstruk yang sama dan dimensi yang sesuai (Gascón, dkk, 2013).

Skala optimisme yang digunakan merupakan skala modifikasi dari Revised Life Orientation Test (LOT-R) yang dikembangkan oleh Scheier, Carver, dan Bridges (1994) untuk mengukur optimisme pada individu. LOT-R merupakan skala pengukuran yang dibangun berdasarkan optimisme sebagai suatu unidimensi (Burke, dkk, 2000; Vautier, Raufaste, \& Cariou, 2003). Scheier, Carver, dan Bridges (1994) melaporkan bahwa Cronbach's alpha coefficient dari LOT-R adalah sebesar 0.78 .

\section{HASIL DAN PEMBAHASAN \\ Hasil}

Uji hipotesis dilakukan melalui uji mediasi dengan menggunakan analisis regresi multiple linear. Baron dan Kenny (1986) menjelaskan bahwa model mediasi menggambarkan mekanisme ataupun hubungan antara variabel independen dan variabel dependen melalui variabel penjelas ketiga, yaitu variabel mediator. Uji korelasi yang dilakukan pada variabel work engagement, iklim organisasi dan optimisme menunjukkan korelasi yang signifikan yaitu 0,000 ( $\mathrm{p}<0.05)$. Baron \& Kenny (1996) menyatakan bahwa hasil uji korelasi yang signifikan memenuhi syarat untuk melakukan analisis regresi sebagai tahap uji mediasi selanjutnya. 


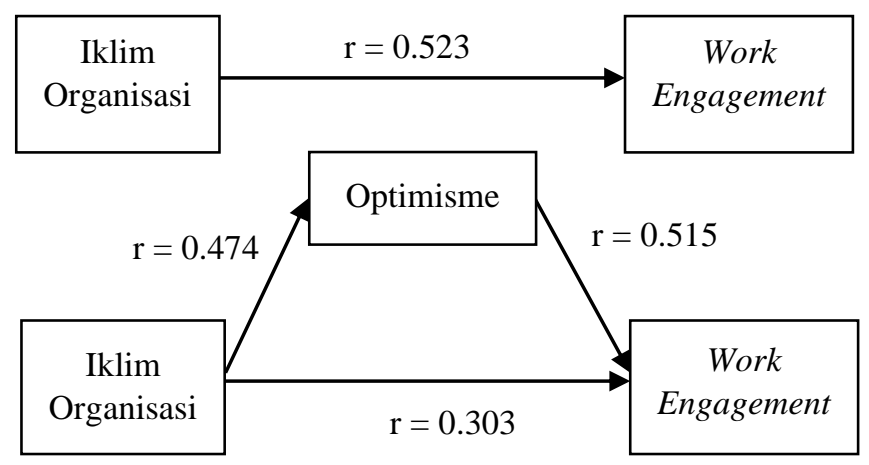

Gambar 1. Model mediasi

Baron dan Kenny (1986) menyatakan bahwa model mediasi terjadi jika pengaruh optimisme tetap signifikan terhadap work engagement setelah mengendalikan iklim organisasi. Nilai signifikansi optimisme terhadap work engagement setelah mengendalikan iklim organisasi adalah 0.005 ( $\mathrm{p}<0.05$ ). Lebih lanjut variabel iklim organisasi masih berpengaruh secara signifikan terhadap work engagement ketika mediator dikontrol dengan nilai signifikansi 0.004 ( $\mathrm{p}<0.05$ ) sehingga dapat disimpulkan bahwa optimisme merupakan variabel mediator yang efektif. Meskipun model mediasi yang terjadi merupakan mediasi parsial.

\section{Pembahasan}

Penelitian ini menunjukkan bahwa optimisme memainkan peran penting dalam memediasi hubungan antara iklim organisasi dengan work engagement, meskipun optimisme hanya merupakan mediator parsial. Hal tersebut sejalan dengan hasil penelitian oleh Xanthopulou, dkk. (2007) bahwa optimisme merupakan mediator parsial atas hubungan lingkungan dengan work engagement. Lebih lanjut Judd dan Kenny (MacKinnon, Fairchild, \& Fritz, 2010) menyatakan bahwa tidak realistik mengharapkan mediator tunggal akan menjelaskan sepenuhnya hubungan antara variabel dependen dan independen.

Hasil penelitian ini menemukan bahwa optimisme mampu menjadi mediator yang baik bagi pengaruh iklim organisasi terhadap work engagement. Optimisme berperan terhadap bagaimana individu menghadapi pekerjaanya, dimana individu yang optimis akan mengharapkan kesuksesan ketika menghadapi tantangan (Sweetman \& Luthan, 2010).

Xanthopoulou, dkk. (2007) memaparkan bahwa lingkungan maupun job resources dapat meningkatkan personal resources sehingga dapat menghasilkan psychological dan organizational outcomes. Iklim organisasi dalam penelitian ini terdiri dari enam komponen, yaitu beban kerja, kontrol, reward, komunitas, keadilan, serta nilai-nilai. Beban kerja yang sesuai akan meningkatkan optimisme individu dimana individu akan menganggap hambatan yang dihadapi sebagai tantangan (Scheier \& Carver, 2003). Hal tersebut pada akhirnya akan membuat individu untuk bekerja dengan lebih semangat, memberikan usaha yang lebih pada pekerjaanya, dan tetap tekun meskipun menghadapi kesulitan dalam pengerjaannya (Avey, Wernsing, \& Luthans, 2008; Schaufeli \& Bakker, 2006). Penelitian lebih lanjut yang dilakukan oleh Karasek (dalam Sweetman \& Luthans, 2010) menunjukkan bahwa kontrol terhadap pekerjaan mampu meningkatkan optimisme seseorang dalam penyelesaian pekerjaannya. Hal tersebut juga pada akhirnya mampu mengurangi cynicism dan meningkatkan dedikasi karyawan dengan rasa kontrol pribadi terhadap tanggung jawab yang diberikan. 
Hasil penelitian Torp, dkk (2012) menunjukkan bahwa dukungan sosial secara signifikan berkorelasi dengan tingginya work engagement pada karyawan. Lebih lanjut Clark (Mc Ginnis, 1995) menyatakan bahwa optimisme dipengaruhi oleh lingkungan dan orang sekitar. Adanya dukungan yang diberikan oleh lingkungan sekitar membuat karyawan menjadi lebih positif dalam memandang segala sesuatu yang dihadapi sehingga dapat membuat karyawan menjadi lebih asyik dan bahagia dengan pekerjaan yang digelutinya. Job resources dipandang sebagai suatu instrumental bagi karyawan untuk berperan secara penuh terhadap pekerjaannya (Schaufeli \& Bakker, 2004). Hasil dari penelitian ini menunjukkan satu langkah yang lebih dimana job resource dapat meningkatkan optimisme karyawan dan membuatnya merasa lebih mampu dalam mengontrol lingkungan mereka (Luthans, dkk., 2006). Hal tersebut membuat karyawan lebih percaya diri dan bangga dengan pekerjaannya dan menemukan makna di dalamnya sehingga membuat karyawan untuk engaged terhadap pekerjaan tersebut (Hackman \& Oldham, 1980).

Hal lain yang ditemukan dalam penelitian ini adalah terdapat perbedaan work engagement yang signifikan jika ditinjau dari usia dan lama kerja karyawan. Nilai rata-rata work engagement tertinggi berada pada rentang usia 36 - 40 tahun sementara untuk lama kerja berada pada rentang 13 - 16 tahun. Baik pada rentang usia maupun lama kerja karyawan menunjukkan bahwa work engagement karyawan akan terus meningkat hingga batas tertentu kemudian akan mengalami sedikit penurunan nilai rerata dan kemudian kembali meningkat. Hasil penelitian longitudinal dilakukan oleh Hakanen dan Schaufeli (2012) menunjukkan bahwa burnout diprediksi gejala depresi dan ketidakpuasan sementara work engagement memiliki efek negatif pada gejala depresi dan efek positif pada kepuasan kerja bahkan setelah disesuaikan untuk dampak burnout di setiap kesempatan. Adanya dimensi kebermanfaatan ini sebagai dimensi tambahan yang dimana didalamnya mencakup rasa syukur, mengambil hikmah, dan memberi pada orang lain menunjukkan adanya sisi religiusitas pada karyawan di Indonesia. Hasil penelitian yang dilakukan oleh Bickerton, dkk. (2012) menunjukkan bahwa adanya spiritual resources dapat menjaga keberlanjutan work engagement karyawan.

Perbedaan work engagement yang sangat signifikan juga terlihat pada status karyawan, dimana karyawan dengan SK PNS memiliki rerata nilai work engagement yang lebih tinggi dibandingkan dengan SK Rektor dan SK Dekan. Hobfoll (deLange, dkk., 2008) mengemukakan bahwa karyawan yang engaged akan lebih baik memanfaatkan peluang promosi yang akan meningkatkan kapasitas mereka dalam regulasi emosi. Lebih lanjut hasil penelitian longitudinal yang dilakukan oleh deLange, dkk. (2008) menunjukkan bahwa work engagement pada karyawan stayers akan mengalami penurunan sementara promotion makers akan menunjukkan peningkatan work engagement.

\section{Keterbatasan Penelitian}

Penelitian telah menyumbangkan bukti empiris mengenai peran optimisme sebagai mediator parsial atas pengaruh iklim organisasi terhadap work engagement pada karyawan. Meskipun demikian, penelitian ini merupakan cross sectional study sehingga membatasi kesimpulan mengenai hubungan dari ketiga variabel. Desain longitudinal masih perlu dilakukan untuk validasi dari penemuan ini dari waktu ke waktu dalam rangka memberikan pemahaman mengenai hubungan kausalitas. Keterbatasan kedua, seluruh data yang dikumpulkan merupakan survei melalui self-reports sehingga data yang diperoleh cenderung subyektif, akan lebih menarik untuk menggunakan penilaian lain dalam penelitian masa depan untuk menghindari masalah ini terutama pada skala iklim organisasi yang menilai tentang bagaimana lingkungan kerja karyawan. Ketiga, penelitian ini menggunakan subjek penelitian yang homogen sehingga masih perlu untuk melakukan pengujian validitas eksternal dari penemuan ini untuk populasi kerja yang berbeda. 


\section{KESIMPULAN DAN SARAN}

Berdasarkan hasil penelitian dapat disimpulkan bahwa optimisme dapat menjadi mediator yang efektif atas pengaruh iklim organisasi terhadap work engagement meskipun hanya sebagai mediator parsial. Iklim organisasi yang kondusif dapat meningkatkan optimisme karyawan dan membuatnya merasa lebih mampu dalam mengontrol lingkungan kerjanya. Hal tersebut membuat karyawan lebih percaya diri dan bangga dengan pekerjaannya dan menemukan makna di dalamnya sehingga membuat karyawan untuk engaged terhadap pekerjaan yang digelutinya..

Penelitian ini menunjukkan bahwa pemberdayaan sumber daya kerja dengan mediator optimisme dapat menciptakan keterlibatan kerja. Organisasi dapat meningkatkan work engagement pada karyawan dengan memberikan beban kerja yang sesuai, kontrol terhadap pekerjaan, reward, dan nilai-nilai yang sesuai. Selain daripada itu adanya kegiatan-kegiatan yang dapat memediasi hubungan antarkaryawan juga dibutuhkan mengingat pentingnya rekan kerja yang saling mendukung untuk menciptakan kepercayaan diri karyawan dan iklim kerja yang kondusif. (Inou, dkk., 2010; Landsberis dalam Leiter \& Maslach, 2005; Schaufeli \& Bakker, 2004; Torp, dkk., 2012).

Hasil penelitian ini juga menunjukkan adanya perbedaan work engagement jika ditinjau dari usia dan lama kerja karyawan. Hal tersebut sesuai dengan hasil penelitian yang menunjukkan bahwa job resources dan personal resources dapat berfluktuasi (Xanthopoulou, dkk., 2009) sehingga dapat menjadi masukan bagi peneliti selanjutnya untuk melakukan penelitian longitudinal. Selain dari pada itu adanya dimensi kebermanfaatan yang ditemukan oleh peneliti juga masih perlu untuk dilakukan penelitian lebih lanjut sehingga dapat ditemukan konstrak work engagement yang sesuai di Indonesia.

\section{DAFTAR PUSTAKA}

Avey, J. B.., Wernsing, T.S., \& Luthans, F (2008). Can positive employees help positive organizational change? Impact of psychological capital and emotions on relevant attitudes and behaviors. Journal of Applied Behavioral Science, 44, 48 - 70.

Bakker, A. B., Albrecht, S. L., \& Leiter, M. P. (2011). Key questions regarding work engagement. European Journal of Work and Organizational Psychology, 20 (1), 428 .

Bakker, A. B., \& Demerouti, E. (2007). The job demands-resources model: State of the art. Journal of Managerial Psychology, 22 (3), 309-328.

Bakker, A. B., \& Sanz-Vergel, A. I. (2013). Weekly work engagement and flourishing: The role of hindrance and challenge job demands. Journal of Vocational Behavior, 83, $397-409$.

Bakker, A. B., \& Xanthopoulou, D. (2013). Creativity and charisma among female leaders: The role of resources and work engagement. The International Journal of Human Resource Management, 24 (14), 2760-2779.

Baron, R. M. \& Kenny, D. A. (1986). The moderator-mediator variable distinction in social psychological research: Conceptual, strategic, and statistical considerations. Journal of Personality and Social Psychology, 5 (6), 1173-1182.

Bickerton, G. R., Miner, M. H., Dowson, M., \& Griffin' B. (2012). Spiritual resources and work engagement among religious workers: A three-wave longitudinal study. Journal 
of Occupational and Organizational Psychology, 87(2), 370-391. DOI: $10.1111 /$ joop.12052.

Burke, K. L., Joyner, A. B., Czech, D. R., \& Wilson, M. J . (2000). An investigation of concurrent validity between two optimisme/pessimism questionnaires: the life orientation test-revised and the optimisme pessimism scale.Current Psychology; Developmental, Learning, Personality, Social, 19 (2), 129-136.

Cho, J., Laschinger, H. K. S., Wong, C. (2006). Workplace empowerment, work engagement and organizational commitment of new graduate nurses. Nursing Research, 19 (3), 43 60 .

deLange, A. H., Witte, H. D., Notelaers, G. (2008). Should I stay or should I go? Examining longitudinal relations among job resources and work engagement for stayers versus movers. Work \& Stress, 22 (3), 201-223. DOI: 10.1080/02678370802390132.

Federici, R. A., \& Skaalvik, E. M. (2011). Principal self-efficacy and work engagement: assessing a Norwegian Principal Self-Efficacy Scale. Social Psychology of Education, $14,575-600$.

Gascón, S., Leiter, M. P., Stright, N., Santed, M. A., Marín, J. M., Andrés, E., Martinez, A. A., \& Campayo, J. G., (2013). A factor confirmation and convergent validity of the "areas of worklife scale" (AWS) to Spanish translation. Health and Quality of Life Outcomes, 11 (63), 1-11.

Hackman, J. R., \& Oldham, G. R. (1980). Work redisign. Reading, MA: Addison Wesley.

Hakanen, J. J., \& Schaufeli, W. B. (2012). Do burnout and work engagement predict depressive symptoms and life satisfaction? A three-wave seven-year prospective study. Journal of Affective disorder, 141, 415-424. doi:10.1016/j.jad.2012.02.043.

Jezzi, M. W. (2006). The moderating role of optimism as related to work resources and work engagement (Master's thesis). Available from ProQuest Disertations and Theses database. (UMI No. 1438571).

Laba, K. (2012). Effects of happiness and psychological meaningfulness on support and engagement in the workplace among women. Industrial/Organisational/Work International Journal of Psychology, 47 (1), 486-558.

Leiter, M. P., \& Maslach, C. (2005). A mediation model of job burnout. In Antoniou, A.S.G., \& Cooper, C.L. (Eds.). Research companion to organizational health psychology (hal. 544-564). Cheltenham, UK: Edward Elgar.

Leiter, M. P., \& Maslach, C. (2011). Areas of Worklife Scale Manual. (5 $5^{\text {th }}$ ed.). Palo Alto, CA: Mindgarden Publishing.

Luthans, F., Avey, J. B., Avolio, B. J. Norman, S. M., \& Combs, G. M. (2006). Psychological capital development: Toward a micro-intervention. Journal of Organizational Behavior, 27, 387-393. 
MacKinnon, D. P., Fairchild, A. J., \& Fritz, M. S. (2010). Mediation analysis. Annual Review of Psychology, 58 (593).

Maslach, C., \& Leiter, M. P. (2008). Early predictors of job burnout. Journal of Applied Psychology, 93 (3), 498-512.

Neiva, E., \& Nery, V. (2012). Change reactions: The role of change context and attitudes toward change. Industrial/Organisational/Work International Journal of Psychology, 47 (1), 486-558.

Othman, N., Ghazali, Z., \& Ahmad, S. (2013, June). Resilience and work engagement: A stitch to nursing care quality. Paper Presented at $3^{\text {rd }}$ International Conference on Management, Hydro Hotel, Penang, Malaysia. ISBN: 978-967-5705-11-3.

Peterson, C., \& Bassio, L. M. (2002). Optimism and physical well-being. Dalam E. C. Chang (Ed.), Optimism and pessimism: Implications for theory, research, and practice (hal.127-145). Washington, DC: American Psychological Association.

Reichers, A. E., \& Schneider, B. (1990). Climate and culture: An evolution of constructs. In B. Schneider (Ed.), Organizational climate and culture. San Francisco: Jossey-Bass.

Salanova, M., \& Schaufeli, W. B. (2008). A cross-national study of work engagement as a mediator between job resources and proactive behavior. The International Journal of Human Resource Management, 19 (1), 116-131.

Schaufeli, W. B. \& Bakker, A. B. (2004). Job demands, job resources, and their relationship with burnout and engagement: A multi-sample study. Journal of Organizational Behavior, 25, 293-315.

Schaufeli, W. B. \& Bakker, A. B. (2006). The measurement of work engagement with a short questionnaire: A Cross-national study. Educational and Psychological Measurement, 66 (4), 701-716.

Scheier, M. F., \& Carver, C. S. (1985). Optimism, coping, and health: Assessment and implications of generalized outcome expectancies. Health Psychology, 4, 219-247.

Scheier, M. F., \& Carver, C. S. (2003). Self-regulatory processes and responses to health threats: effects of Optimism on well-being. Dalam Jerry Suls \& Kenneth A. Wallston (Ed.). Social psychological foundations of health and illness. USA: Blackwell Publishing Ltd.

Scheier, M. F., Carver, C. S., \& Bridges, M. W. (1994). Distinguishing optimism from neuroticism (and trait anxiety, self-mastery, and self-esteem): A re-evaluation of the Life Orientation Test. Journal of Personality and Social Psychology, 67, 1063-1078.

Simbula, S., Panari, C., Guglielmi, D., \& Fraccaroli, F. (2011). Teachers' Well-being and Effectiveness: The role of the interplay between job demands and job resources. Social and Behavioral Sciences, 69, 729-738.

Sweetman, D., \& Luthans, F. (2010). The power of positive psychology: Psychological Capital and work engagement. Dalam A.B. Bakker \& M.P. Leiter (Eds.), Work 
engagement: A handbook of essential theory and research (hal. 147-163). New York: Psychology Press

Torp, S., Grimsmo, A., Hagen, S., Duran, A., \& Gudbergsson, S. B. (2012). Work engagement: A practical measure for workplace health promotion? Health Promotion International, 1-10.

Vautier, S., Raufaste, E., \& Cariou, M. (2003). Dimensionality of the revised life orientation test and the status of the filler items. International Journal of Psychology, 38, 390400 .

Xanthopoulou, D., Bakker, A. B., Demerouti, E., \& Schaufeli, W. B. (2007). The Role of Personal Resources in the Job Demands-Resources Model. International Journal of Stress Management, 14 (2), 121-141.

Xanthopoulou, D., Bakker, A. B., Demerouti, E., \& Schaufeli, W. B. (2009). Work engagement and financial returns: A diary study on the role of job and personal resources. Journal of Occupational and Organizational Psychology, 82, 183-200. 